\title{
Level of knowledge, attitudes and interest of Turkish high school students towards cancer
}

Health Education Journal 2020, Vol. 79(8) 875-887

(C) The Author(s) 2020

Article reuse guidelines: sagepub.com/journals-permissions DOI: $10.1177 / 0017896920923724$ journals.sagepub.com/home/hej

@SAGE

\author{
Ilgin Yildirim Usta ${ }^{(D)}$ and Armagan Ateskan \\ Graduate School of Education, Bilkent University, Ankara, Turkey
}

\begin{abstract}
Objective: This study investigated Turkish high school students' knowledge about risk factors for cancer, their interest in the disease, and their affective and behavioural attitudes towards it.

Design: Quantitative survey.

Setting: Data collection took place in three private schools in Central Turkey and one private school in Eastern Turkey.

Method: Students ( $N=275 ; 56 \%$ female students, $44 \%$ male students) completed a paper-and-pencil questionnaire and described their level of knowledge regarding cancer risk factors, as well as their attitudes and interest in the disease. For data analysis, the Statistical Package for Social Sciences (SPSS, v.24.0) was used.

Results: Results indicated that most students succeeded in identifying nearly all carcinogenic (except for overweight) and non-carcinogenic risk factors. In addition, while most participants held negative attitudes towards cancer, they typically did not exhibit cancer protective behaviours, and most participants were not interested in cancer as a topic.

Conclusion: Exploring high school students' levels of knowledge, attitudes and interests in regard to cancer may provide curriculum developers with information that enables the development of effective cancer education for Turkish high school students.
\end{abstract}

\section{Keywords}

Attitudes, cancer, high school students, knowledge, risk factors, Turkey

\section{Corresponding author:}

Ilgin Yildirim Usta, Graduate School of Education, Bilkent University, Main Campus-G Building, Bilkent, 06800 Ankara, Turkey.

Email: ilginyildirimusta@alumni.bilkent.edu.tr 


\section{Introduction}

Cancer is one of the major causes of death in both developed and developing countries. Owing to overpopulation and an ageing population, the number of cancer patients has gradually increased. In addition, lifestyle choices such as smoking, physical inactivity, the consumption of unhealthy nutrients and changes in reproductive practices have increased the number of cancer cases (Torre et al., 2015). In one study, researchers analysed 36 cancer types in 185 countries and estimated that, in 2018 alone, 18.1 million people were diagnosed with cancer and 9.6 million people died from cancer (Bray et al., 2018). By 2030, it is expected that there will be 22 million new cases of cancer per annum (Ferlay et al., 2015). Therefore, precautionary acts to help diminish cancer incidents are warranted, such as providing individuals with appropriate cancer education.

In the light of this, several studies have shown that health education has a positive effect on knowledge and attitudes towards health issues (Haghani et al., 2017; Soweid et al., 2003; Wang et al., 2015). In China, Wang et al. (2015) found that middle school students who received nutrition education knew more about the nutritional content of vegetables, dairy products, beans and meat; the percentage of students who thought nutrition was important for a healthy life was higher in the educated group; and finally, this group consumed vegetables and had breakfast every day. Similarly, Hill et al. (2010) explored the effects of cancer education on adults' level of knowledge and attitudes. They found that participants' level of knowledge increased after they were provided with cancer education. In addition, the education programme changed participants' fatalistic attitude towards cancer, with some beginning to behave in a more proactive way towards cancer after being provided with cancer education. Research therefore indicates that education has a noticeable effect on students' knowledge and attitudes towards this disease. Consequently, we believe that developing interventions that are focused on students' needs may prove to be even more effective in the fight against cancer.

Notwithstanding this, many countries have struggled to provide appropriate cancer education. For example, Heuckmann and Asshoff (2014) reported that cancer is not widely taught about in schools in Germany. Moreover, if teachers do not want to teach this topic, it does not have be taught. In contrast, another study found that British teachers were enthusiastic with regard to teaching students about cancer (Cribb, 1990). However, a different study claimed that teachers in the United Kingdom did not possess adequate knowledge about cancer causing them to feel uncomfortable teaching the topic (Carey, 1992). Sugisaki et al. (2014) stated that, in Japan, cancer education materials - and those from related topics - exist only for use in high schools, whereas the primary school curriculum contains information about other diseases.

The International Baccalaureate (IB) Programme, designed to provide an education to students from 3 to 19 years of age, comprises four programmes: the Primary Years Programme (PYP), the Middle Years Programme (MYP), the Diploma Programme (DP) and the Career-related Programme (CP). Currently, the curriculum has been implemented in over 150 countries and in approximately 5,000 schools (International Baccalaureate Organization [IBO], n.d.). Both the PYP and the MYP do not include any knowledge with regard to cancer (IBO, 2008, 2009, 2014b, 2014c), and the DP makes mention only of certain types of cancer and associated risk factors (IBO, 2014a).

In Turkey, no information is available regarding the type of cancer education included in physical education courses and in science and technology courses at primary and middle schools following the Ministry of National Education (MoNE, 2013d, 2013e, 2013f) curriculum. Notwithstanding this, information about cancer is present in the MoNE's biology and health curricula. Specifically, Turkish schools provide students with weekly, 1-hour health courses in the ninth grade (14-15 years of age). In the health course curriculum, Unit 5 is called 'Harmful Habits for Health' and emphasises the relationship between cancer and smoking. Unit 7, called 'Basic Concepts and Principles 


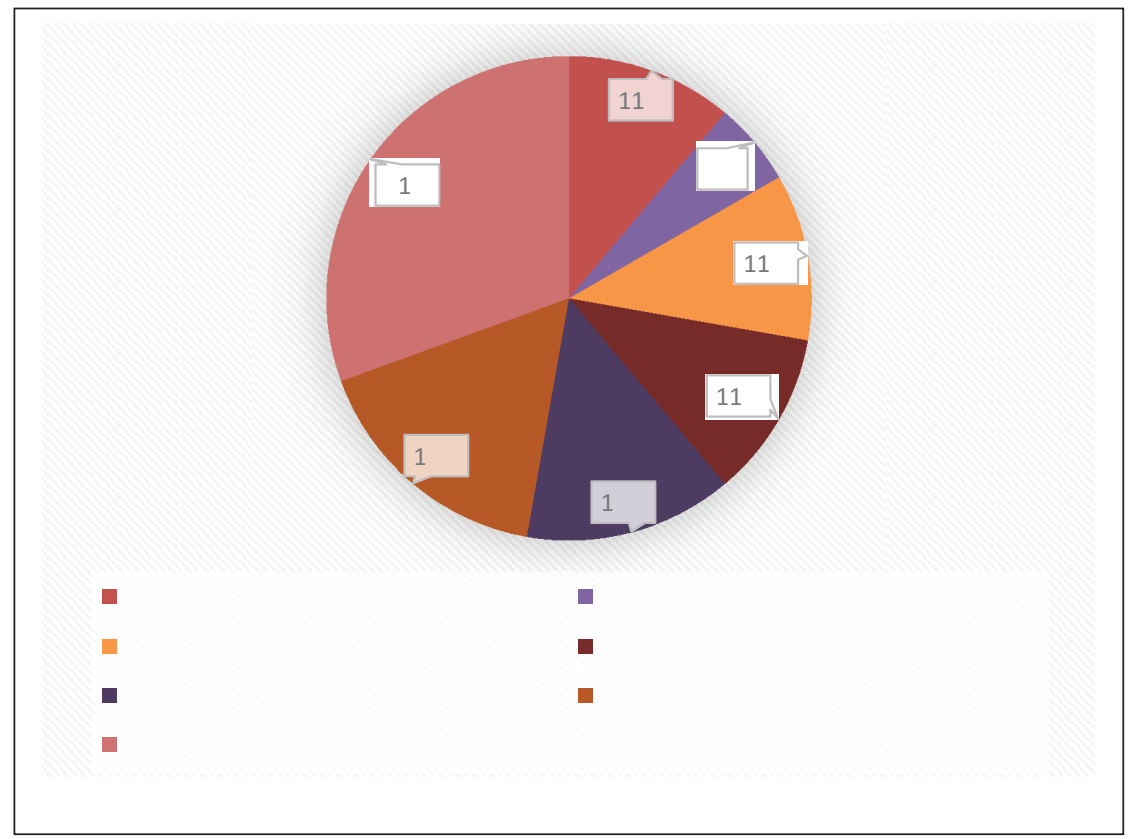

Figure I. Topics taught to Grade 9 students (aged I4-15years of age) through the National Ministry of Education School Health course.

about Diseases', also provides some basic information concerning cancer risk factors and symptoms. Its purpose is to signal the importance of an early diagnosis for cancer and a variety of other health conditions. In addition, this unit contains material on how to prevent these diseases and identifies activities related to cancer in which students can take part (MoNE, 2012). Figure 1 identifies relevant units in the Turkish health course and lists percentages according to the total lesson hours required for the unit to be completed.

Within the biology curriculum taught in Turkish high schools, cancer is typically taught in the 10th grade (15-16years of age) in the context of mitosis in the unit on 'Reproduction'. It is also taught in the 'From Gene to Protein' unit, where current cancer treatment methods are examined (MoNE, 2013a). Despite the fact that cancer is considered an interdisciplinary topic in scientific studies, there is no information about cancer contained in the chemistry or physics curricula of Turkish high schools (MoNE, 2013b, 2013c).

Previous studies have shown that providing students with a curriculum that is compatible with their level of knowledge helps them adopt healthier lifestyles (Knighting et al., 2011). Moreover, to allow people to change their understanding and behaviours towards cancer, it is necessary to identify their beliefs - and the sources of these beliefs - regarding this disease (Schernhammer et al., 2010). Thus, we believe a curriculum that is designed to be in accordance with Turkish students' knowledge, beliefs and attitudes towards cancer may enable students to more effectively pursue behaviours that prevent cancer and other chronic diseases.

The following research questions were identified.

1. What are high school students' levels of knowledge about risk factors for cancer?

2. What are high school students' affective and behavioural attitudes towards cancer?

3. What are the aspects of cancer in which high school students are most interested? 


\section{Methods}

\section{Research design and participants}

This was a quantitative study that utilised a survey for data collection. We used convenience sampling to obtain the required data, and participants were chosen from three private schools in Central Turkey and one private school in Eastern Turkey. These four schools were used because they had a partnership with the university in which the research was carried out and they were IB schools.

Data were collected via a paper-and-pencil questionnaire that was developed by Heuckmann and Asshoff (2014). After receiving permission from the creators, we translated the questionnaire from English into Turkish. To check its validity, the questionnaire was then back-translated from Turkish into English. The questionnaire was distributed to 275 students ( $56 \%$ female students; $44 \%$ male students; age range, 16-19years). All participants completed the questionnaire, which lead to a response rate of $100 \%$. Students from all four schools were of broadly similar social status, educational background and were of the same ethnic origin. In our study sample, $82(30 \%)$ participants followed the MoNE curriculum exclusively, while 193 (70\%) followed both the IBDP and MoNE curricula.

Approval to conduct the study was provided by the General Directorate of Private Educational Institutions of the MoNE (approval number: 95178074-405.01-E.3022111) and participants' parents. Before completing the questionnaire, participants were provided with instructions, assured that they could skip any question and/or stop the questionnaire at any time, and told that all responses would remain confidential.

\section{Instruments}

The data collection questionnaire consisted of four parts. The first part contained questions pertaining to demographic information, including gender, age, grade, which curriculum was being followed, parental educational background, family monthly income and whether anyone in their families had suffered from cancer (if yes, which type of cancer). The second part contained a 14-statement dichotomous (yes/no) scale which was used to assess participants' level of knowledge about cancer risk factors. Participants were asked whether they perceived a relationship between cancer and statements from the questionnaire and responded with either 'yes' or 'no' for each statement. Participants gained one point for each correct answer. The reliability of this scale was analysed using Cronbach's alpha, which was $\alpha=.783$.

The third part included 15 items that assessed participants' attitudes towards cancer on a 4-point Likert-type scale $(1=$ strongly disagree, $2=$ disagree, $3=$ agree and $4=$ strongly agree $)$. This part was divided into two components: affective and behavioural. For the first of these components, there were seven items $(\alpha=.897)$ that assessed negative emotional responses towards cancer. For the second, there were eight items $(\alpha=.837)$ that assessed proactive behaviours towards cancer; it was divided into three subsections: communication (four items; $\alpha=.842$ ), lifestyle choices (two items; $\alpha=.803$ ) and social engagement (two items; $\alpha=.610$ ).

The fourth part included 27 items that assessed students' interest in cancer through various cancer types, treatment methods and information on the biological processes of cancer. Participants responded using a 4-point Likert-type scale ( $1=$ not interesting, $2=$ somewhat interesting, $3=$ interesting and $4=$ very interesting). Reliability was analysed using Cronbach's alpha, which was $\alpha=.970$.

\section{Data analysis}

We utilised the Statistical Package for Social Sciences (SPSS, v.24.0) for data analysis. First, we computed normality analyses for items located in the second (i.e. level of knowledge about cancer 
risk factors), third (i.e. attitudes towards cancer) and fourth (i.e. interest in cancer) parts of the questionnaire. Based on the results of our normality analyses, we then used parametric tests to assess each research question.

All items were analysed using descriptive statistics (i.e. mean value, standard deviation, frequency and percentages). In this study, the mean values of items in the third and fourth parts of the questionnaire provided information regarding students' views about cancer. That is, mean values greater than 2.5 indicated that more than $50 \%$ of participants tended to agree with - or were interested in - the statement; mean values smaller than 2.5 indicated that less than $50 \%$ of participants tended to disagree with - or were not interested in - the statement, given that we used a 4-point rating scale $(1=$ strongly disagree to $4=$ strongly agree; $1=$ not interesting to $4=$ very interesting $)$. In SPSS, mean values were computed based on the following formula to assess students' attitudes and interests with respect to cancer:

([number of students who chose response strongly disagree/not interesting] $\times$ [weighting of response strongly disagree/not interesting] $+[$ number of students who chose response disagree/somewhat interesting] $\times$ [weighting of response disagree/somewhat interesting $]+[$ number of students who chose response agree/interesting] $\times$ [weighting of response agree/interesting] + [number of students who chose response strongly agree/very interesting] $\times$ [weighting of response strongly agree/very interesting])/(total number of students who answered the questions)

\section{Results}

\section{Students' level of knowledge regarding cancer risk factors}

Most participants chose the correct answers for carcinogenic factors (Table 1). More specifically, most participants answered items G (89.1\%) and I (87.9\%) correctly. However, many participants $(60.3 \%)$ incorrectly answered item $\mathrm{H}$ (being overweight is non-carcinogenic). In addition, most participants were successful at identifying non-carcinogenic factors, as most answered items B (52.2\%), J (73.9\%), L (84.3\%) and N (90.5\%) correctly.

\section{Students' attitudes towards cancer (affective and behavioural)}

As shown in Table 2, most participants tended to agree with the affective dimension statements $(M=2.72)$. Item $\mathrm{K}$ had the highest mean value $(M=2.85)$, with which $65.9 \%$ of the participants $(n=178)$ agreed. In contrast, the lowest mean value occurred for item $\mathrm{F}(M=2.53)$, with which $52.8 \%$ of participants $(n=141)$ agreed.

As shown in Table 3, most students tended to disagree with items in the communication subsection $(\mathrm{M}, \mathrm{N}, \mathrm{O}$ and $\mathrm{P})$ of the behavioural dimension $(M=2.18)$. The lowest mean value occurred for item O $(M=1.97)$, with which most participants $(75 \% ; n=200)$ disagreed. The mean values of items $\mathrm{M}, \mathrm{N}$ and $\mathrm{P}$ were 2.04, 2.45 and 2.26, respectively, and many participants disagreed with these items $(70.4 \%, n=188 ; 50 \%, n=133$; and $57.5 \%, n=153$, respectively). In contrast, most participants tended to agree with statements in the lifestyle choices subsection $(M=2.79)$, with mean values for items $\mathrm{Q}$ and $\mathrm{R}$ being 2.92 and 2.67, respectively. Many participants agreed with these items $(69.0 \%, n=185$; and $57.8 \%, n=156$, respectively). Similarly, most participants tended to agree with the social engagement subsection $(M=2.71)$, with mean values for items $\mathrm{S}$ and $\mathrm{T}$ being 2.53 and 2.90, respectively. Many participants agreed with these items $(51.1 \%, n=137$; and $69.3 \%, n=187$, respectively). 
Table I. Participants' (number and percentages) who identified statements as carcinogenic and noncarcinogenic.

\begin{tabular}{|c|c|c|c|c|}
\hline & & $\begin{array}{l}\text { Number of participants who } \\
\text { identified the statement as } \\
\text { carcinogenic }\end{array}$ & $\begin{array}{l}\text { Number of participants who } \\
\text { identified the statement as } \\
\text { non-carcinogenic }\end{array}$ & $n$ \\
\hline \multirow[t]{2}{*}{$A^{a}$ : Going to the solarium often } & $f$ & 220 & 52 & \multirow[t]{2}{*}{272} \\
\hline & $\%$ & 80.9 & 19.1 & \\
\hline \multirow[t]{2}{*}{$B^{\mathrm{b}}$ : Numerous birthmarks } & $f$ & 130 & 142 & \multirow[t]{2}{*}{272} \\
\hline & $\%$ & 47.8 & 52.2 & \\
\hline \multirow{2}{*}{$\begin{array}{l}C^{\text {a: }} \text { Excessive exposure to } \\
\text { sunlight }\end{array}$} & f & 210 & 63 & \multirow[t]{2}{*}{273} \\
\hline & $\%$ & 76.9 & 23.1 & \\
\hline \multirow[t]{2}{*}{$D^{a}$ : Drinking alcohol } & f & 182 & 91 & \multirow[t]{2}{*}{273} \\
\hline & $\%$ & 66.7 & 33.3 & \\
\hline \multirow{2}{*}{$\begin{array}{l}\text { Ea: Smoking, cigarettes, cigars or } \\
\text { cigarillo }\end{array}$} & $f$ & 236 & 38 & \multirow[t]{2}{*}{274} \\
\hline & $\%$ & 86.1 & 13.9 & \\
\hline \multirow[t]{2}{*}{$F^{a}$ : Consuming drugs } & $f$ & 188 & 84 & \multirow[t]{2}{*}{272} \\
\hline & $\%$ & 69.1 & 30.9 & \\
\hline \multirow[t]{2}{*}{ Ga: Radioactive radiation } & $f$ & 244 & 30 & \multirow[t]{2}{*}{274} \\
\hline & $\%$ & 89.1 & 10.9 & \\
\hline \multirow[t]{2}{*}{$\mathrm{H}^{\mathrm{a}}$ : Overweight } & f & 108 & 164 & \multirow[t]{2}{*}{272} \\
\hline & $\%$ & 39.7 & 60.3 & \\
\hline \multirow[t]{2}{*}{ Ia: Ultraviolet radiation } & $f$ & 240 & 33 & \multirow[t]{2}{*}{273} \\
\hline & $\%$ & 87.9 & 12.1 & \\
\hline \multirow[t]{2}{*}{ J: Hypertension } & f & 71 & 201 & \multirow[t]{2}{*}{272} \\
\hline & $\%$ & 26.1 & 73.9 & \\
\hline \multirow[t]{2}{*}{$\mathrm{K}^{\mathrm{a}}$ : X-ray radiation } & $f$ & 226 & 47 & \multirow[t]{2}{*}{273} \\
\hline & $\%$ & 82.8 & 17.2 & \\
\hline \multirow[t]{2}{*}{$L^{\text {b: }}$ Frequent common cold } & f & 43 & 231 & \multirow[t]{2}{*}{274} \\
\hline & $\%$ & 15.7 & 84.3 & \\
\hline \multirow[t]{2}{*}{$M^{a}$ : Smoking the hookah } & f & 212 & 61 & \multirow[t]{2}{*}{273} \\
\hline & $\%$ & 77.7 & 22.3 & \\
\hline \multirow[t]{2}{*}{$\mathrm{N}^{\mathrm{b}}$ : Contact with cancer patients } & f & 26 & 248 & \multirow[t]{2}{*}{274} \\
\hline & $\%$ & 9.5 & 90.5 & \\
\hline
\end{tabular}

f: frequency; \%: percentage of students' answers.

${ }^{a}$ Carcinogenic risk factor.

bNon-carcinogenic risk factor.

\section{Students' interest in cancer}

As shown in Table 4, for the interest in cancer scale, the highest mean values occurred for items A $(M=2.79)$ and $\mathrm{J}(M=2.71)$. Many participants were interested/very interested in both items $(64.9 \%$, $n=174$; and $59.8 \%, n=158)$. In contrast, the lowest mean values occurred for items $\mathrm{D}(M=2.10)$ and $\mathrm{F}(M=2.12)$. Many participants were not/somewhat interested in both items $(69.2 \%, n=184$; and $69.8 \%, n=183)$. 
Table 2. Participants' level of agreement with the statements in the affective dimension of the attitude towards cancer scale.

\begin{tabular}{|c|c|c|c|c|c|c|c|c|}
\hline & & $\begin{array}{l}\text { Strongly } \\
\text { disagree }\end{array}$ & Disagree & Agree & $\begin{array}{l}\text { Strongly } \\
\text { agree }\end{array}$ & $n$ & Mean & $S D$ \\
\hline \multicolumn{7}{|l|}{ Affective dimension of attitude } & 2.72 & .80721 \\
\hline \multirow{2}{*}{$\begin{array}{l}\text { F: Faced with the idea of getting } \\
\text { cancer, I feel depressed }\end{array}$} & $f$ & 59 & 67 & 81 & 60 & \multirow[t]{2}{*}{267} & \multirow[t]{2}{*}{2.53} & \multirow[t]{2}{*}{1.070} \\
\hline & $\%$ & 22.1 & 25.1 & 30.3 & 22.5 & & & \\
\hline \multirow{2}{*}{$\begin{array}{l}\text { G: I have negative thoughts when } \\
\text { thinking about cancer }\end{array}$} & $f$ & 31 & 62 & 93 & 81 & \multirow[t]{2}{*}{267} & \multirow[t]{2}{*}{2.84} & \multirow[t]{2}{*}{.989} \\
\hline & $\%$ & 11.6 & 23.2 & 34.8 & 30.3 & & & \\
\hline \multirow{2}{*}{$\begin{array}{l}\mathrm{H} \text { : Thinking about getting cancer } \\
\text { makes me feel anxious }\end{array}$} & $f$ & 38 & 54 & 98 & 77 & \multirow[t]{2}{*}{267} & \multirow[t]{2}{*}{2.80} & \multirow[t]{2}{*}{1.012} \\
\hline & $\%$ & 14.2 & 20.2 & 36.7 & 28.8 & & & \\
\hline \multirow{2}{*}{$\begin{array}{l}\text { I: Faced with the idea of getting } \\
\text { cancer, I feel uncertain }\end{array}$} & $f$ & 49 & 58 & 103 & 57 & \multirow[t]{2}{*}{267} & \multirow[t]{2}{*}{2.63} & \multirow[t]{2}{*}{1.015} \\
\hline & $\%$ & 18.4 & 21.7 & 38.6 & 21.3 & & & \\
\hline \multirow{2}{*}{$\begin{array}{l}\text { J: I feel worried when thinking } \\
\text { about cancer }\end{array}$} & $f$ & 39 & 65 & 99 & 67 & \multirow[t]{2}{*}{270} & \multirow[t]{2}{*}{2.72} & \multirow[t]{2}{*}{.996} \\
\hline & $\%$ & 14.4 & 24.1 & 36.7 & 24.8 & & & \\
\hline \multirow{2}{*}{$\begin{array}{l}\text { K: I feel sad when thinking about } \\
\text { cancer }\end{array}$} & $f$ & 38 & 54 & 88 & 90 & \multirow[t]{2}{*}{270} & \multirow[t]{2}{*}{2.85} & \multirow[t]{2}{*}{1.038} \\
\hline & $\%$ & |4.I & 20.0 & 32.6 & 33.3 & & & \\
\hline \multirow[t]{2}{*}{ L: Cancer makes me feel scared } & $f$ & 39 & 68 & 80 & 82 & \multirow[t]{2}{*}{269} & \multirow[t]{2}{*}{2.76} & \multirow[t]{2}{*}{1.042} \\
\hline & $\%$ & 14.5 & 25.3 & 29.7 & 30.5 & & & \\
\hline
\end{tabular}

SD: standard deviation; f: frequency; \%: percentage of students' answers.

\section{Discussion}

\section{Students' level of knowledge regarding cancer risk factors}

Results showed most participants succeeded in identifying risk factors for cancer, with more than $80 \%$ of participants identifying the following items as carcinogenic: going to the solarium often; smoking; and radioactive, ultraviolet and x-ray radiation (items A, E, G, I and K of Table 1). This result may be due to television and media, as Oakley et al. (1995) showed that most of their participants (105 out of 226) aged 9-16 years reported acquiring information about cancer from television and the media. Similarly, Karayurt et al. (2008) explored high school students' level of knowledge about breast cancer risk factors, and $48.6 \%$ of their participants stated that the media was their primary information source for breast cancer. Thus, television and media can be very effective for creating awareness and educating young people regarding cancer risk factors, symptoms and prevention.

Although Anderson et al. (2015) identified a positive correlation between cancer and obesity, $60 \%$ of our participants stated there was no relationship between cancer and being overweight. Similarly, in Karayurt et al.'s (2008) study, high school students had insufficient knowledge regarding the relationship between breast cancer and obesity. This lack of knowledge may be due to insufficient information regarding the relationship between cancer and obesity in both the IBDP and Turkish high school curricula. In the latter, although the ninth-grade health curriculum includes information on the importance of a balanced diet, in Unit 3 ('Development and Protection of Health'), the term overweight - and its risk factors - is not associated with cancer and its carcinogenic characteristics are not emphasised (MoNE, 2012). Similarly, the ninth-grade Turkish high school biology curriculum (MoNE, 2013a) aims to teach the importance of a balanced diet and the 
Table 3. Participants' level of agreement with statements from the behavioural dimension of the attitudes towards cancer scale.

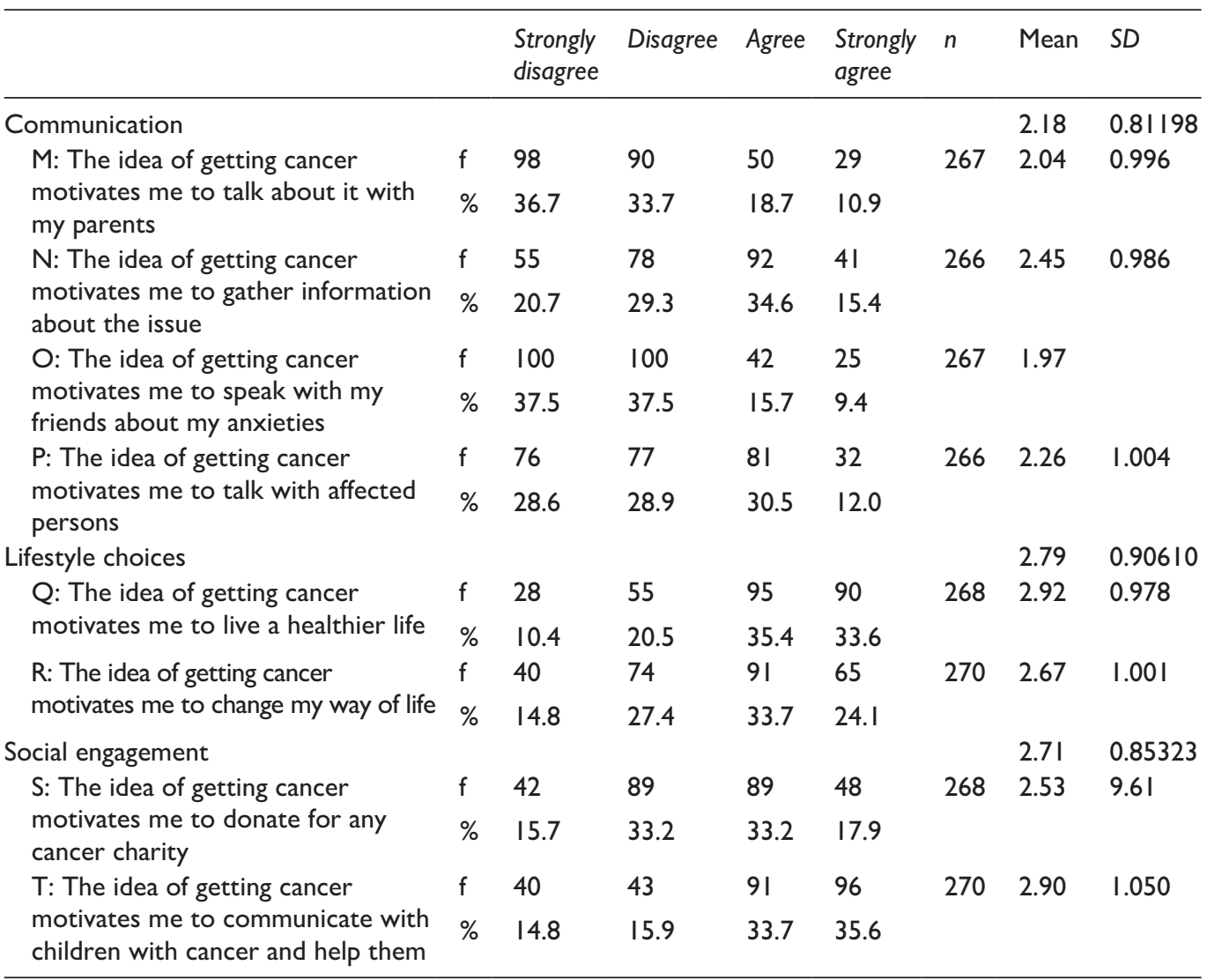

SD: standard deviation; f: frequency; \%: percentage of students' answers.

relationship between obesity, diabetes and insulin resistance, but does not associate obesity with cancer. Thus, both the national and IBDP curricula should emphasise the correlation between cancer and obesity under an appropriate topic in biology and health lessons. In addition, other cancer risk factors could be added, for example, in Unit 3 of the IBDP, radiation and some chemicals (e.g. benzo[a]pyrene and nitrosamines) are already presented as causes of mutation and cancer (Allott, 2014). This presence provides an opportunity to include additional information concerning carcinogenic chemicals and their connection to most common cancer types.

Although most participants succeeded in identifying non-carcinogenic factors, the item 'numerous birthmarks' (item B in Table 1) showed similar percentages for 'yes' and 'no' answers. This result may be due to a lack of information about skin cancer symptoms in both Turkish government (biology and health) and the IBDP (biology) curricula (IBO, 2009; MoNE, 2012, 2013a). Importantly, including accurate information about skin cancer within the curriculum may diminish students' uncertainty. Furthermore, under the 'Ecology' Unit, the IBDP curricula might usefully encourage students to discuss the effects of earth's depleted ozone layer on ultraviolent radiation as it affects the human skin. 
Table 4. Participants' level of interest in cancer.

\begin{tabular}{|c|c|c|c|c|c|c|c|c|}
\hline & & $\begin{array}{l}\text { Not } \\
\text { interesting }\end{array}$ & $\begin{array}{l}\text { Somewhat } \\
\text { interesting }\end{array}$ & Interesting & $\begin{array}{l}\text { Very } \\
\text { interesting }\end{array}$ & $n$ & Mean & $S D$ \\
\hline \multirow[t]{2}{*}{ A: General human biology } & $f$ & 42 & 52 & 95 & 79 & 268 & 2.79 & 1.037 \\
\hline & $\%$ & 15.7 & 19.4 & 35.4 & 29.5 & & & \\
\hline \multirow[t]{2}{*}{ B: Cancer in general } & $f$ & 45 & 90 & 88 & 44 & 267 & 2.49 & 0.959 \\
\hline & $\%$ & 16.9 & 33.7 & 33.0 & 16.5 & & & \\
\hline \multirow[t]{2}{*}{ C: Leukaemia (blood cancer) } & $f$ & 58 & 68 & 83 & 57 & 266 & 2.52 & 1.058 \\
\hline & $\%$ & 21.8 & 25.6 & 31.2 & 21.4 & & & \\
\hline \multirow[t]{2}{*}{ D: Bladder cancer } & $f$ & 91 & 93 & 47 & 35 & 266 & 2.10 & 1.020 \\
\hline & $\%$ & 34.2 & 35.0 & 17.7 & 13.2 & & & \\
\hline \multirow[t]{2}{*}{ E: Breast cancer } & $f$ & 75 & 62 & 75 & 54 & 266 & 2.41 & 1.103 \\
\hline & $\%$ & 28.2 & 23.3 & 28.2 & 20.3 & & & \\
\hline \multirow[t]{2}{*}{ F: Gallbladder cancer } & $f$ & 85 & 98 & $4 I$ & 38 & 262 & 2.12 & 1.025 \\
\hline & $\%$ & 32.4 & 37.4 & 15.6 & 14.5 & & & \\
\hline \multirow[t]{2}{*}{ G: Brain tumours } & $f$ & 63 & 43 & 80 & 80 & 266 & 2.67 & 1.141 \\
\hline & $\%$ & 23.7 & 16.2 & 30.1 & 30.1 & & & \\
\hline \multirow[t]{2}{*}{$\mathrm{H}$ : General cancer symptoms } & $f$ & 56 & 64 & 81 & 65 & 267 & 2.58 & 1.076 \\
\hline & $\%$ & 21.1 & 24.1 & 30.5 & 24.4 & & & \\
\hline \multirow[t]{2}{*}{ I: Cancer genesis } & $f$ & 48 & 60 & 83 & 75 & 266 & 2.70 & 1.068 \\
\hline & $\%$ & 18.0 & 22.6 & 31.2 & 28.2 & & & \\
\hline \multirow[t]{2}{*}{ J: General cancer therapies } & $f$ & 46 & 60 & 83 & 75 & 264 & 2.71 & 1.062 \\
\hline & $\%$ & 17.4 & 22.7 & 31.4 & 28.4 & & & \\
\hline \multirow[t]{2}{*}{ K: Chemotherapy } & $f$ & 55 & 67 & 77 & 67 & 266 & 2.59 & 1.079 \\
\hline & $\%$ & 20.7 & 25.2 & 28.9 & 25.2 & & & \\
\hline \multirow[t]{2}{*}{ L: Tumour removal by surgery } & $f$ & 53 & 58 & 75 & 80 & 266 & 2.68 & 1.105 \\
\hline & $\%$ & 19.9 & 21.8 & 28.2 & 30.1 & & & \\
\hline \multirow[t]{2}{*}{ M: Alternative cancer therapies } & $f$ & 63 & 57 & 74 & 72 & 266 & 2.58 & 1.124 \\
\hline & $\%$ & 23.7 & 21.4 & 27.8 & 27.1 & & & \\
\hline
\end{tabular}

SD: standard deviation; f: frequency; \%: percentage of students' answers.

Our results corroborate Heuckmann and Asshoff's (2014) findings, as most participants succeeded in identifying both non-carcinogenic and carcinogenic factors. Although the percentage of participants in Heuckmann and Asshoff's (2014) study who successfully identified obesity as a carcinogenic factor was much lower (18.7\%) than what was observed in our study, our results still corroborate previous research, as many of our participants did not identify obesity as being carcinogenic.

In addition, smoking and sunlight (items $\mathrm{E}$ and $\mathrm{C}$; Table 1) were correctly identified as cancer risk factors by approximately $80 \%$ of our participants. This result corroborates findings by Oakley et al. (1995) who asked participants to list carcinogenic risk factors of which they were already aware. In this case, most participants wrote down that smoking and sunburn are major risk factors for cancer. Similarly, Knighting et al. (2011) investigated children's understanding of cancer by 
asking participants to draw and write anything about cancer. They found that smoking and sunshine were the most drawn/written risk factors for cancer.

\section{Students' attitudes towards cancer in the affective and behavioural dimension}

Our results indicate that most participants agreed with all affective dimension items regarding attitudes towards cancer (i.e. most participants experienced negative emotions when they thought about cancer; see Table 2). Although current cancer treatment methods are introduced in a specific unit ('From Gene to Protein') in the Turkish 12th-grade biology course (MoNE, 2013a) - and the importance of healthy living habits for disease prevention is highlighted through both biology and health curricula in Turkish high schools (MoNE, 2012, 2013a) - these lessons may not be sufficient to diminish students' negative emotions regarding cancer. Previous research by Heuckmann and Asshoff (2014) found that most participants exhibited negative emotions towards cancer. Similarly, Knighting et al. (2011) found that students aged 8-11 years associated cancer with death and held negative perceptions of the disease.

One explanation why participants felt negative emotions towards cancer may be related to the idea that, owing to external factors, cancer is uncontrollable. This conclusion has been corroborated in prior research. For example, a study that was conducted with advanced-stage cancer patients showed that health locus of control had an important role in patients' feelings, as those who experienced an external health locus of control tended to feel more negative emotions (e.g. death anxiety), as these patients held the belief that their life course depended on external factors and not on themselves (Shukla and Rishi, 2018). In the light of these findings, teachers may be well placed to investigate the reasons behind these negative thoughts. Doing so should lead to the development of interventions and curricula that can help diminish students' existing negative emotions and beliefs pertaining to cancer. Moreover, if changes are made in national and international curricula to meet this goal, students may be able to strengthen their beliefs regarding cancer controllability, thereby leading them to take action against this disease.

Regarding the behavioural dimensions of participants' attitudes towards cancer, the communication subsection was mostly disagreed upon by participants. Specifically, the idea of developing cancer did not motivate most participants to speak with someone and/or to acquire more information. Oakley et al. (1995) found that teenagers thought teachers were the group of adults with which they felt most confident talking about cancer, after which parents came second. As a result, well-educated teachers may be able to exert a positive effect on students' attitudes towards cancer by designing classes that enable students to openly talk with teachers.

In contrast, most participants agreed with statements from the lifestyle choices and social engagement subsections. In particular, the idea of developing cancer motivated most students to live a healthy life, to change their lifestyle and to help someone with cancer. Heuckmann and Asshoff (2014) reported that the idea of developing cancer motivated more than half of their participants to live a healthy life and to help children with cancer.

\section{Students' interest in learning about cancer}

Overall, most participants were not interested in cancer; however, more than half were interested in human biology, cancer treatment methods, cancer symptoms, cancer genesis, brain tumours and leukaemia. Given that students learn about certain risk factors, symptoms and treatment methods of cancer through their health and biology courses in the Turkish high school/IBDP curricula, we thought participants' initial interest in biology and health might first be evoked by such courses, leading to these results. 
In contrast to our findings, Heuckmann and Asshoff (2014) reported that the students in their study exhibited a high interest in cancer. Topics which participants found interesting in both our study and Heuckmann and Asshoff's (2014) included brain tumours, leukaemia, cancer symptoms and cancer genesis. In addition, according to Heuckmann and Asshoff (2014), students' interest in cancer is useful for cancer education because it can stimulate communication about this topic. Furthermore, different cancer types (i.e. the topic which stimulated students' interest the most) can be included as part of cancer education curricula (Heuckmann and Asshoff, 2014).

Based on our findings, 'Physiology' may be an appropriate topic in which information about specific cancer types could be provided to Turkish students. In each section of the physiology unit in the Biology curriculum, both the IBDP and the Turkish national curricula provide space to insert new material on causes, symptoms, treatment, diagnosis and prevention of specific types of cancer. For example, the 'Digestion' and 'Human Nutrition' topics in the IBDP biology curriculum could be used to highlight the relationship between colon cancer and the lower consumption of high fibre foods. Furthermore, the importance of imaging techniques for diagnosing brain tumours and other cancer types using magnetic resonance imaging could be examined in the 'Functions of the Brain' topic. One topic participants were especially interested in was 'general cancer therapies'. Current treatment methods could be addressed in the physiology component of both the IBDP and the national curricula, while reference to new and future treatment methods could be included in the 'Biotechnology and Informatics' topic of the IBDP curricula.

\section{Limitations}

This study used a convenience sample and participants consisted exclusively of Turkish students from a very small number of private and IB high schools. Therefore, our results and discussion are not generalisable for all high school students. In future research, researchers may wish to choose state schools and conduct a nationwide survey. Moreover, given our participants were high school students, to obtain a more comprehensive understanding of students' cancer perceptions, future research should be conducted at different school levels.

\section{Concluding comments}

In conclusion, findings from this study may be useful for developing future cancer educational programmes in Turkey. In doing so, the following specific issues could usefully be addressed:

- Identify being overweight as being a key carcinogenic factor;

- Identify numerous birthmarks as being a non-carcinogenic factor;

- Describe current cancer treatment methods so as to help reduce students' negative attitudes towards cancer;

- Promote the early recognition of cancer symptoms, which may enhance motivation towards learning about cancer, given that participants found it an interesting topic;

- Identify healthy and unhealthy lifestyle habits that may prevent and lead to cancer;

- Promote the adoption of healthy lifestyle habits.

\section{Funding}

The author(s) received no financial support for the research, authorship and/or publication of this article. 


\section{ORCID iD}

Ilgin Yildirim Usta (iD https://orcid.org/0000-0003-3184-1104

\section{References}

Allott A (2014) Biology for the IB Diploma. Oxford: Oxford University Press.

Anderson AS, Key TJ, Norat T, et al. (2015) European code against cancer 4th edition: Obesity, body fatness and cancer. Cancer Epidemiology 39(1): S34-S45.

Bray F, Ferlay J, Soerjomataram I, et al. (2018) Global cancer statistics 2018: GLOBOCAN estimates of incidence and mortality worldwide for 36 cancers in 185 countries. CA: A Cancer Journal of Clinicians 68(6): 394-424.

Carey P (1992) Teachers' attitudes to cancer education: A discussion in the light of a recent English survey. Journal of Cancer Education 7(2): 153-161.

Cribb A (1990) School teachers' perceptions of the relative importance of cancer education in the United Kingdom. Journal of Cancer Education 5(4): 225-229.

Ferlay J, Soerjomataram I, Dikshit R, et al. (2015) Cancer incidence and mortality worldwide: Sources, methods and major patterns in GLOBOCAN 2012. International Journal of Cancer 136(5): E359-E386.

Haghani S, Shahnazi H and Hassanzadeh A (2017) Effects of tailored health education program on overweight elementary school students' obesity-related lifestyle: A school-based interventional study. Oman Medical Journal 32(2): 140-147.

Heuckmann B and Asshoff R (2014) German high school students' attitudes and interest in cancer and factors influencing proactive behaviour for cancer prevention. Journal of Cancer Education 29(3): 497-505.

Hill TG, Briant KJ, Bowen D, et al. (2010) Evaluation of Cancer 101: An educational program for native settings. Journal of Cancer Education 25(3): 329-336.

International Baccalaureate Organization (IBO) (2008) Primary Years Programme: Science scope and sequence. Available at: https://resources.ibo.org/pyp/resource/11162-occ-filep_0_scixx_sco_0807_1_e/ data/p_0_scixx_sco_0807_2_e.pdf (accessed 7 February 2019).

International Baccalaureate Organization (IBO) (2009) Primary Years Programme: Personal, social and physical education scope and sequence. Available at: https://resources.ibo.org/pyp/resource/11162-32408/ data/p_0_psexx_sco_0911_2_e.pdf (accessed 7 February 2019).

International Baccalaureate Organization (IBO) (2014a) Diploma Programme: Biology guide. Available at: https://resources.ibo.org/dp/subject-group/Biology/resource/11162-occ-file-d_4_biolo_gui_1402_1_e/ data/d_4_biolo_gui_1402_6_e.pdf (accessed February 7 2019).

International Baccalaureate Organization (IBO) (2014b) Middle Years Programme: Physical and health education guide. Available at: https://resources.ibo.org/myp/subject-group/Physical-health-and-education/ resource/11162-32959/data/m_7_physe_guu_1405_5_e.pdf (accessed 7 February 2019).

International Baccalaureate Organization (IBO) (2014c) Middle Years Programme: Sciences guide. Available at: https://resources.ibo.org/myp/subject-group/Sciences/resource/11162-32957/data/m_4 scien_guu_1405_5_e.pdf (accessed 7 February 2019).

International Baccalaureate Organization (IBO) (n.d.) About the IB. Available at: https://www.ibo.org/aboutthe-ib/ (accessed 8 December 2019).

Karayurt O, Özmen D and Çetinkaya AÇ (2008) Awareness of breast cancer risk factors and practice of breast self-examination among high school students in Turkey. BMC Public Health 17(8): 359.

Knighting K, Rowa-Dewar N, Malcolm C, et al. (2011) Children's understanding of cancer and views on health-related behaviour: A 'draw and write' study. Child: Care, Health and Development 37(2): 289-299.

Ministry of National Education (MoNE) (2012) Teaching program of secondary school health course.

Ministry of National Education (MoNE) (2013a) Teaching program of biology course (Grade 9-12). Available at: http://talimterbiye.mebnet.net/Ogretim\%20Programlari/lise/ana.html

Ministry of National Education (MoNE) (2013b) Teaching program of chemistry course (Grade 9-12). Available at: http://talimterbiye.mebnet.net/Ogretim\%20Programlari/lise/ana.html 
Ministry of National Education (MoNE) (2013c) Teaching program of physics course (Grade 9-12). Available at: http://talimterbiye.mebnet.net/Ogretim\%20Programlari/lise/ana.html

Ministry of National Education (MoNE) (2013d) Teaching program of physical education course (Grade 9-12).

Ministry of National Education (MoNE) (2013e) Teaching program of science and technology course (Grade 4-5). Available at: http://talimterbiye.mebnet.net/Ogretim\%20Programlari/ilkokul/ana.html

Ministry of National Education (MoNE) (2013f) Teaching program of science and technology course (Grade 6-8). Available at: http://talimterbiye.mebnet.net/Ogretim\%20Programlari/ortaokul/ana.html

Oakley A, Bendelow G, Barnes J, et al. (1995) Health and cancer prevention: Knowledge and beliefs of children and young people. British Medical Journal 310: 1029-1033.

Schernhammer E, Haidinger G, Waldhör T, et al. (2010) A study of trends in beliefs and attitudes toward cancer. Journal of Cancer Education 25(2): 211-216.

Shukla P and Rishi P (2018) Health locus of control, psychosocial/spiritual well-being and death anxiety among advanced-stage cancer patients. Psychological Studies 63: 200-207.

Soweid RAA, El Kak F, Major SC, et al. (2003) Changes in health-related attitude and self-reported behaviour of undergraduate students at the American University of Beirut following a health awareness course. Education for Health 16(3): 265-278.

Sugisaki K, Ueda S, Monobe H, et al. (2014) Cancer understanding among Japanese students based on a nationwide survey. Environmental Health and Preventive Medicine 19(6): 395-404.

Torre LA, Bray F, Siegel RL, et al. (2015) Global cancer statistics, 2012. CA: A Cancer Journal of Clinicians 65(2): 87-108.

Wang D, Stewart D, Chang C, et al. (2015) Effect of a school-based nutrition education program on adolescents' nutrition-related knowledge, attitudes and behaviour in rural areas of China. Environmental Health and Preventive Medicine 20(4): 271-278. 